A model for the bond between concrete and reinforcement

K. Lundgren and K. Gylltoft

Published in Magazine of Concrete Research, see journal homepage http://www.icevirtuallibrary.com/content/journals

"Permission is granted by ICE Publishing to print one copy for personal use. Any other use of these PDF files is subject to reprint fees." 


\title{
A model for the bond between concrete and reinforcement
}

\author{
Karin Lundgren* and Kent Gylltoft* \\ Chalmers University of Technology
}

The bond mechanism between deformed bars and concrete is known to be influenced by a number of parameters, such as the strength of the surrounding structure, the presence of splitting cracks and yielding of the reinforcement. However, when reinforced concrete structures are analysed with finite element models, it is quite common to assume that the bond stress depends solely on the slip. A new model has been developed, which is specially suited for detailed three-dimensional analyses. In this new model, the splitting stresses of the bond action are included, and the bond stress depends not only on the slip, but also on the radial deformation between the reinforcement bar and the concrete. Bar pull-out tests with various geometries and with both monotonic and cyclic loading have been analysed. The results show that the new model is capable of predicting splitting failures and the loss of bond if the reinforcement is yielding, as well as dealing with cyclic loading in a physically reasonable way.

\section{Introduction}

When modelling reinforced concrete structures with the finite element method, the most common method has been to use a bond-slip relation for the interaction between the reinforcement bars and the surrounding concrete. However, bond action causes not only bond stresses, but also splitting stresses, as was shown by Tepfers, ${ }^{1}$ among others. If the concrete surrounding the reinforcement bar is well confined, meaning that it can withstand these splitting stresses, a pull-out failure is obtained (Fig. 1). If the concrete cannot withstand these splitting stresses, splitting cracks in the concrete will cause a decrease of the bond capacity. Also, if the reinforcement starts yielding, the bond capacity will decrease. ${ }^{2}$ A disadvantage of using predefined bondslip relations as input for analyses is that these circumstances must be known in advance-if the concrete will split, or if the reinforcement will yield-so that the correct bond-slip relation can be given. $\operatorname{Cox}^{3}$ and Akesson ${ }^{4}$ have developed other bond models that include the splitting stresses. None of them has, however, been shown to describe the loss of bond when the

\footnotetext{
* Division of Concrete Structures, Chalmers University of Technology, S-412 96 Göteborg, Sweden.
}

(MCR 785) Paper received 20 May 1999; last revised 14 September 1999; accepted 27 October 1999

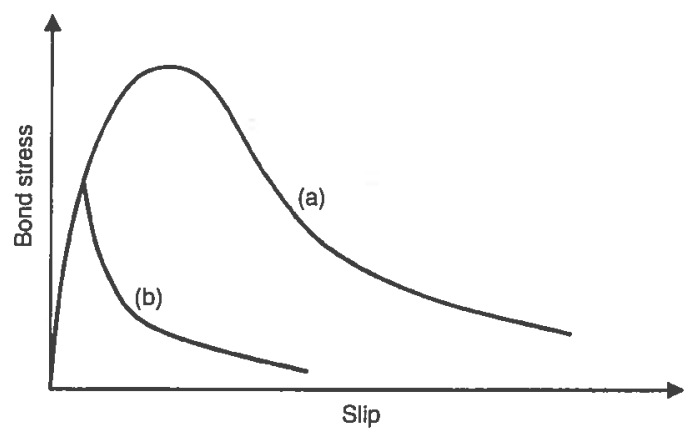

Fig. 1. Schematic bond-slip relationship: (a) pull-out failure; (b) splitting failure, or loss of bond due to yielding of the reinforcement

reinforcement starts yielding, and Ảkesson's model is not suited for cyclic loading. In the applications of the model we had in mind, cyclic loading often prevails.

A new model has therefore been developed, which includes the splitting stresses. With the same input parameters, this new model results in various bond-slip curves, depending on the confinement of the surrounding structure, and on whether the reinforcement is yielding or not. The effect of cyclic loading with varying slip direction is also important for the bond resistance. Therefore, this effect has also been included in the model. The model is presented here, together with results from finite element analyses of pull-out tests. For more details, see Lundgren. ${ }^{5}$ 


\section{Theoretical model}

In the finite element program DIANA, there are interface elements available, which describe a relation between the tractions $\mathbf{t}$ and the relative displacements $\mathbf{u}$ in the interface. These interface elements are used at the surface between the reinforcement bars and the concrete. The physical interpretations of the variables $t_{\mathrm{n}}, t_{\mathrm{t}}, u_{\mathrm{n}}$ and $u_{\mathrm{t}}$ are shown in Fig. 2. The interface elements have, initially, a thickness of zero.

\section{Elasto-plastic formulation}

The model is a frictional model, using elasto-plastic theory to describe the relations between the stresses and the deformations. The relation between the tractions $\mathbf{t}$ and the relative displacements $\mathrm{u}$ is in the elastic range:

$$
\left[\begin{array}{c}
t_{\mathrm{n}} \\
t_{\mathrm{t}}
\end{array}\right]=\left[\begin{array}{cc}
D_{11} & \frac{\left|u_{\mathrm{t}}\right|}{u_{\mathrm{t}}} D_{12} \\
0 & D_{22}
\end{array}\right]\left[\begin{array}{l}
u_{\mathrm{n}} \\
u_{\mathrm{t}}
\end{array}\right]
$$

where $D_{12}$ is normally negative, meaning that slip in either direction will cause negative $t_{\mathrm{n}}$, that is compressive forces directed outwards in the concrete. Furthermore, the model has yield lines, flow rules, and hardening laws. The yield lines are described by two yield functions, one describing the friction, $F_{1}$, assuming that the adhesion is negligible:

$$
F_{1}=\left|t_{\mathrm{t}}\right|+\mu t_{\mathrm{n}}=0
$$

The other yield line, $F_{2}$, describes the upper limit at a pull-out failure. This is determined from the stress in the inclined compressive struts that results from the bond action (Fig. 3).

$$
F_{2}=t_{\mathrm{t}}^{2}+t_{\mathrm{n}}^{2}+c t_{\mathrm{n}}=0
$$

For plastic loading along the yield line describing the upper limit, $F_{2}$, an associated flow rule is assumed. For the yield line describing the friction, $F_{1}$, a nonassociated flow rule is assumed, where the plastic part of the deformations is

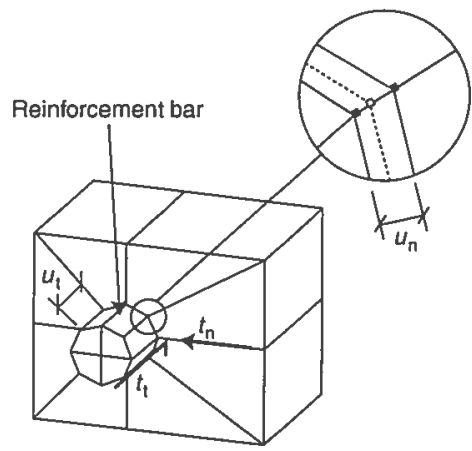

$$
\begin{aligned}
& \mathrm{t}=\left[\begin{array}{l}
t_{n} \\
t_{1}
\end{array}\right]=\left[\begin{array}{l}
\text { normal stress } \\
\text { bond stress }
\end{array}\right] \\
& \mathrm{u}=\left[\begin{array}{l}
u_{n} \\
u_{\mathrm{i}}
\end{array}\right]=\left[\begin{array}{l}
\text { relative normal displacement in the layer } \\
\text { slip }
\end{array}\right]
\end{aligned}
$$

Fig. 2. Physical interpretation of the variables $t_{\mathrm{n}}, t_{\mathrm{t}}, u_{\mathrm{n}}$ and $u_{\mathrm{t}}$

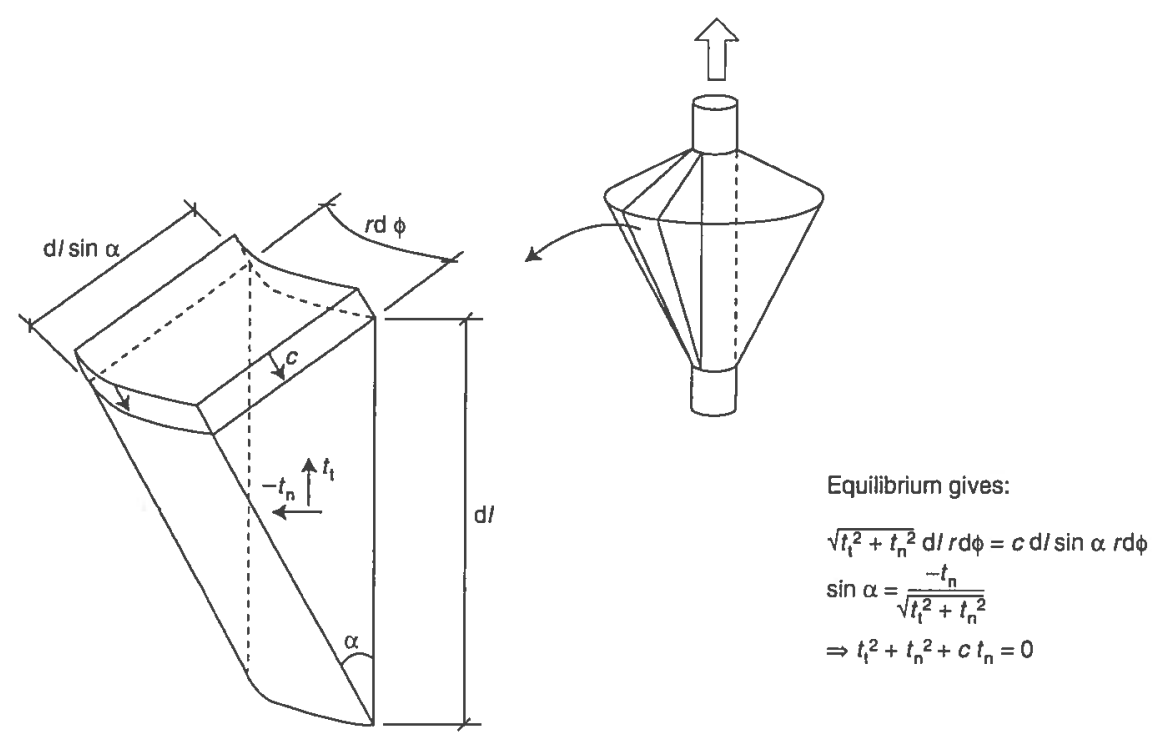

Fig. 3. The stress in the inclined compressive struts determines the upper limit 


$$
\mathrm{d} \mathbf{u}^{\mathrm{p}}=\mathrm{d} \lambda \frac{\partial G}{\partial \mathrm{t}}, G=\frac{\left|u_{\mathrm{t}}\right|}{u_{\mathrm{t}}} t_{\mathrm{t}}+\eta t_{\mathrm{n}}=0
$$

where $\mathrm{d} \lambda$ is the incremental plastic multiplier. The yield lines, together with the direction of the plastic part of the deformations, are shown in Fig. 4. At the corners, a combination of the two flow rules is used; this is known as the Koiter rule.

For the hardening rule of the model, a hardening parameter $\kappa$ is established. It is defined by

$$
\mathrm{d} \kappa=\sqrt{\left(\mathrm{d} u_{\mathrm{n}}^{\mathrm{p}^{2}}+\mathrm{d} u_{\mathrm{t}}^{\mathrm{p}^{2}}\right)}
$$

It can be noted that for monotonic loading, $\mathrm{d} u_{\mathrm{n}}^{\mathrm{p}}$ and the elastic part of the slip are very small compared to the plastic part of the slip, $\mathrm{d} u_{\mathrm{t}}^{\mathrm{p}}$; therefore, the hardening parameter $\kappa$ will be almost equivalent to the slip, $u_{\mathrm{t}}$. The variables $\mu$ and $c$ in the yield functions are assumed to be functions of $\kappa$.

\section{Three-dimensional modelling}

For three-dimensional modelling, a third component is added: the stress acting in the direction around the bar. This is assumed to act independently of the other components. The equation for the elastic stage is then assumed to be

$$
\left[\begin{array}{c}
t_{\mathrm{n}} \\
t_{\mathrm{t}} \\
t_{\mathrm{r}}
\end{array}\right]=\left[\begin{array}{ccc}
D_{11} & \frac{u_{\mathrm{t}}}{\left|u_{\mathrm{t}}\right|} D_{12} & 0 \\
0 & D_{22} & 0 \\
0 & 0 & D_{33}
\end{array}\right]\left[\begin{array}{l}
u_{\mathrm{n}} \\
u_{\mathrm{t}} \\
u_{\mathrm{r}}
\end{array}\right]
$$

The main objective with the stiffness $D_{33}$ is that it prevents the bar from rotating in the concrete. The traction $t_{\mathrm{r}}$ has no influence on the yield lines.

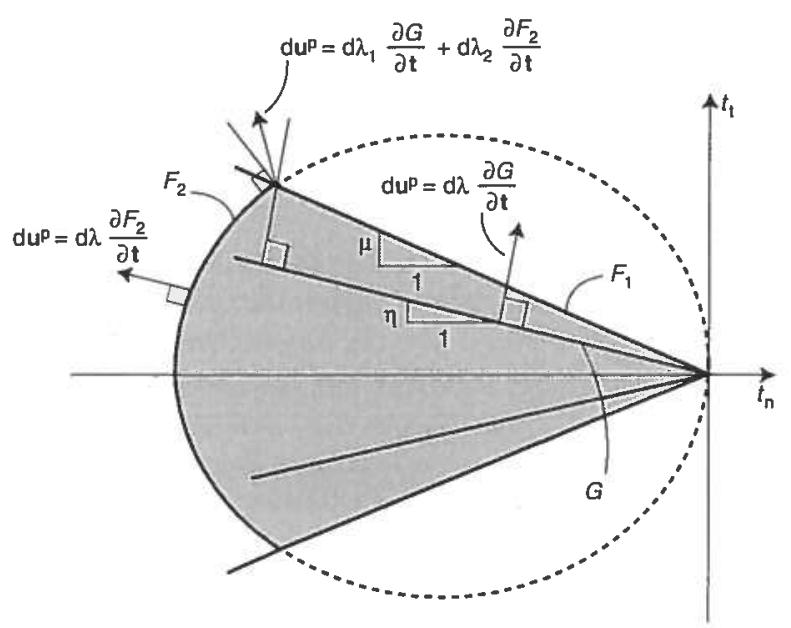

Fig. 4. The yield lines. The plastic part of the deformation, $\mathrm{du}^{\mathrm{p}}$, is given by an associated flow rule at the yield line describing the upper limit, $F_{2}$, and a non-associated flow rule at the yield line describing the friction, $F_{1}$

\section{Damaged/undamaged deformation zones}

A typical response for bond with varying slip direction is with a steep unloading and then an almost constant, low bond stress until the original monotonic curve is reached (Fig. 5(a)). To make the model describe this typical response, a new concept, damaged/ undamaged deformation zone, is used. The idea is that when the reinforcement slips in the concrete, the friction will be damaged in the range of the passed slip. This is a simplified way to describe the damage of the cracked and crushed concrete. In Fig. 5(b), the reinforcement is back in its original position after slipping in both directions. The concrete will then be crushed in the range of the passed slip. This crushed concrete still has some capacity to carry compressive load, but no capacity at all in tension. The friction is therefore assumed to vary in the damaged zone, depending on whether loading is applied in the direction away from, or towards, the original position, as shown in Figs 5(c) and 5(d). It is assumed to immediately drop to a low value $\mu_{\mathrm{d} 0}$ at load reversal, and to keep this value until the original position is reached. For further loading, away from the original position, the friction is assumed to gradually increase, until the undamaged zone is reached and the normal value of $\mu$ is used again. To describe this gradual increase, an equation of the second degree has been chosen.

The parameter $\eta$ also has a lower value in the damaged deformation zone, varying in the same way as just described for the coefficient of friction. This lower value physically corresponds to the fact that the increase in the stresses is lower than in the undamaged deformation zone.

\section{Discussion of the model}

The most important feature of the model is that it applies to both the bond stress and the splitting stress, thus describing the inclined struts that result from the bond action. By modelling the surrounding structure, it is possible to obtain, for example, splitting cracks in the concrete, or cone cracks close to free edges. One of the main ideas of the model is that the complex crushing and cracking of the concrete close to the reinforcement bar is described in a simplified way by decreasing the friction between the reinforcement bar and the concrete. The model is sensitive to the resistance of the surrounding structure, so that if the pressure around the bar, for some reason, is lost, the bond stress will decrease.

To better understand how the model works, a monotonic loading of a pull-out test will be discussed. When the loading starts, there are no initial stresses. This means that the loading will start at point $\mathrm{A}$ in Fig. 6. When a tensile force is applied, loading along yield line $F_{1}$ will occur. For further loading, the coefficient of friction decreases due to the hardening in the model. The loading will therefore follow a curved line as 


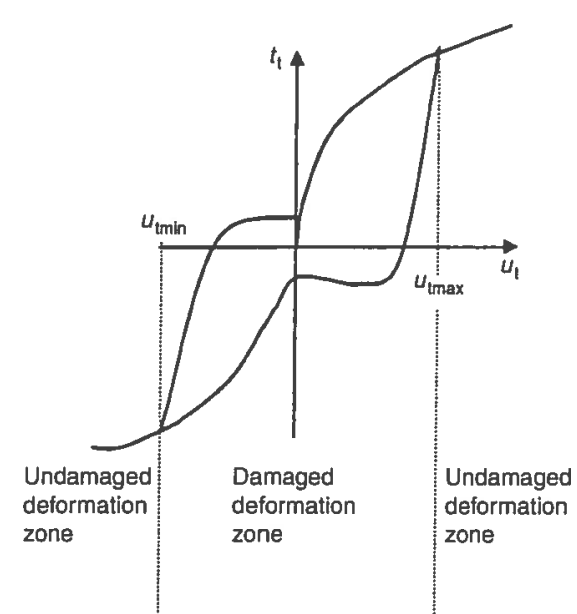

(a)

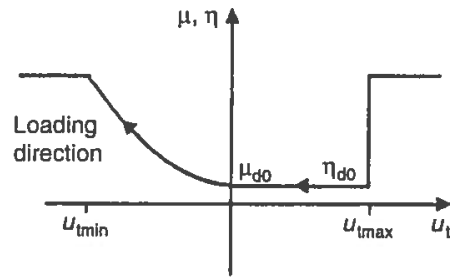

(c)

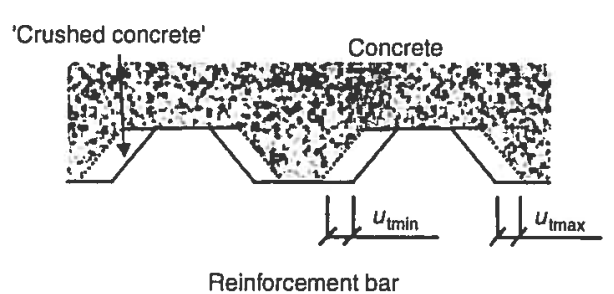

(b)

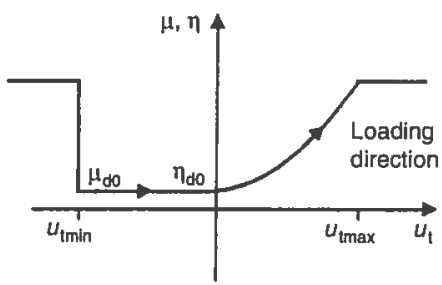

(d)

Fig. 5. (a) One load cycle with varying slip directions. (b) The reinforcement bar is back in its original position, after slipping in both directions. Maximum and minimum values of the slip are especially marked. $(c, d)$ The parameters $\mu$ and $\eta$ vary within the damaged deformation zone, depending on whether the loading is directed towards or away from the original position

....... Initial yleld lines

— Yield lines after hardening

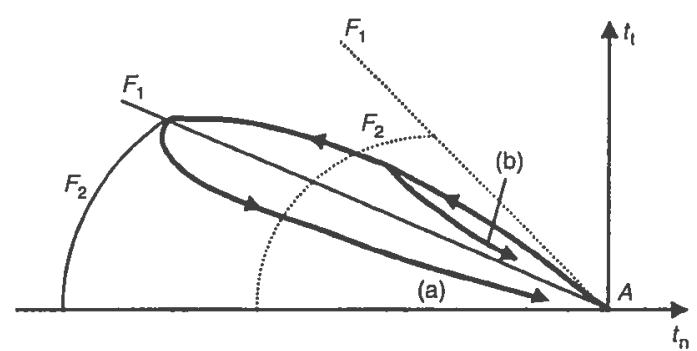

Fig. 6. Various loading paths depending on the failure mode: (a) pull-out failure; (b) splitting failure, or loss of bond due to yielding of the reinforcement

shown in Fig. 6. For the loading along yield line $F_{1}$, an equivalent stiffness matrix $D_{\text {eq }}$ can be deduced:

$$
\mathrm{d} \mathbf{t}=\mathbf{D d} \mathbf{u}^{\mathrm{c}}=\mathbf{D}\left(\mathrm{d} \mathbf{u}-\mathrm{du} \mathbf{u}^{\mathrm{p}}\right)
$$

where, by equation (4)

$$
\mathrm{du} \mathbf{u}^{\mathrm{p}}=\mathrm{d} \lambda \frac{\partial G}{\partial \mathrm{t}}=\mathrm{d} \lambda\left[\begin{array}{c}
\eta \\
\frac{\left|u_{\mathrm{t}}\right|}{u_{\mathrm{t}}}
\end{array}\right]
$$

Loading along the yield line implies that $F_{1}$ equals zero both before and after the loading step, so

$$
\mathrm{d} F_{1}=0
$$

By assuming that the change in $\mu$ is negligible, we thus obtain

$$
\frac{\partial F_{1}}{\partial \mathrm{t}} \mathrm{d} \mathbf{t}=0 \Rightarrow \frac{\left|t_{\mathrm{t}}\right|}{t_{\mathrm{t}}} \mathrm{d} t_{\mathrm{t}}+\mu \mathrm{d} t_{\mathrm{n}}=0
$$

Loading with a positive slip, and a positive bond stress, then gives

$$
\left[\begin{array}{l}
\mathrm{d} t_{\mathrm{n}} \\
\mathrm{d} t_{\mathrm{t}}
\end{array}\right]=\frac{D_{11} D_{22}}{D_{22}+D_{11} \eta \mu+D_{12} \mu}\left[\begin{array}{cc}
1 & -\eta \\
-\mu & \eta \mu
\end{array}\right]\left[\begin{array}{l}
\mathrm{d} u_{\mathrm{n}} \\
\mathrm{d} u_{\mathrm{t}}
\end{array}\right]
$$

This means that the bond stress, $t_{t}$, will depend on both the slip, $u_{\mathrm{t}}$, and the relative normal displacements between the reinforcement bar and the concrete, $u_{n}$. In a pull-out test, this normal displacement will increase with increasing load. This is because the concrete will move away from the reinforcement bar due to the normal stresses, and the radius of the reinforcement bar will decrease due to the Poisson effect. Hence, in equation (7), the parameter $\eta$ must be chosen so that the bond stress will increase for normal loading, that is 
$\eta \mathrm{d} u_{\mathrm{l}}>\mathrm{d} u_{\mathrm{n}}$. If, however, the concrete splits or the reinforcement starts yielding, this normal displacement will start to increase faster. If the parameter $\eta$ then is properly calibrated, the bond stress will decrease, that is $\eta \mathrm{d} u_{\mathrm{t}}<\mathrm{d} u_{\mathrm{n}}$. The loading will thus follow a path as indicated in Fig. 6 with (b). If neither the concrete splits nor the reinforcement starts yielding, the upper limit in the form of the cap $F_{2}$ will be reached. The hardening of this function is chosen to describe the pull-out failure, and the loading path will be as indicated in Fig. 6 with (a). Between these two extreme cases are, of course, many other possible loading paths, where perhaps the initial yield line $F_{2}$ is reached and, after some hardening, splitting occurs.

The discussion above shows two important criteria to take into account when the value of the parameter $\eta$ is chosen. Another important criterion is that the dissipated energy must be positive, that is that the model cannot store any more energy than the elastic one. This criterion leads to a condition for the selected input variables: that $-\mu \leqslant \eta \leqslant \mu$. The model must also give a unique solution for each point. For this criterion to be fulfilled at the corner, $\eta \geqslant\left(\mu^{2}-1\right) / 2 \mu$.

\section{Input parameters for the interface}

Required input data for the interface are the elastic stiffness matrix $\boldsymbol{D}$ in equation (1), the parameter $\eta$ defined in equation (4), and, for loading in the damaged deformation zone, the parameters $\eta_{\mathrm{d} 0}$ and $\mu_{\mathrm{d} 0}$. Furthermore, the functions $\mu(\kappa)$ and $c(\kappa)$ must be chosen. The model is calibrated for reinforcement bars $\mathrm{K} 500 \phi 16$ and normal strength concrete. Before using the values recommended here on other concrete strengths or reinforcement qualities, analyses and comparisons with experimental results are recommended. However, generally speaking, a smoother surface of the reinforcement bar would give lower friction and lower values of the stiffnesses in the elastic stiffness matrix D. A more specific background for the choice of the input parameters can be found Lundgren. ${ }^{5}$

First of all, the stiffness $D_{22}$ in the elastic stiffness matrix $D$ was recognized as the stiffness of the first part, or at unloading, in a bond-slip curve. By assuming that this is proportional to the modulus of elasticity of the concrete, and by comparing with results from experiments, this stiffness was chosen to be

$$
D_{22}=K_{22} E_{\mathrm{c}}, K_{22}=6.0 \mathrm{~m}^{-1}
$$

Next, the stiffnesses $D_{11}$ and $D_{12}$ were determined. The larger $D_{11}$ is chosen to be, the more variation of the stresses along the reinforcement bar is obtained. This variation depends on variations of the strength of the modelled structure, as for example when stirrups are taken into account. To obtain a physically reasonable variation, $D_{11}$ was chosen to be

$$
D_{11}=K_{11} E_{\mathrm{c}}, K_{11}=11.0 \mathrm{~m}^{-1}
$$

The stiffness $D_{12}$ determines how large a part of the Magazine of Concrete Research, 2000, 52, No. 1 normal stresses will remain after unloading. By comparing with results from experiments, $D_{12}$ was chosen to be

$$
D_{12}=-0.9 \frac{D_{22}}{\mu_{\max }}
$$

For three-dimensional modelling, the stiffness $D_{33}$ in equation (6) is also required. A value of $10^{10} \mathrm{~N} / \mathrm{m}^{3}$ was used in all analyses, since it was found that this was enough to prevent the bar from rotating in the concrete.

The parameter $\eta$ is chosen in order to obtain a decreasing bond stress when the concrete around the bar splits, without elastic unloading; see the discussion in the previous section. Through calibration, $\eta$ was chosen to be 0.04 . For loading in the damaged deformation zones, $\eta_{\mathrm{d} 0}$ was chosen to be 0.004 , and the coefficient of friction $\mu_{\mathrm{d} 0}$ was 0.4 .

The function $\mu(\kappa)$ describes how the relation between the bond stress and the normal splitting stress depends on the hardening parameter. Tepfers and Olsson ${ }^{6}$ performed 'ring tests': pull-out tests in concrete cylinders confined by thin steel tubes. They measured the strain in the steel ring and used this to evaluate the normal stress. The results, together with the chosen input for the analyses, are shown in Fig. 7 (a). The chosen input is also selected to match the experimental data of steel-encased pull-out tests carried out by the authors; ${ }^{7}$ see the next section. Since a unique solution should be given at the corner, the coefficient of friction was not assumed to be larger than 1.0.

The variable $c$ represents the stress in the inclined compressive struts as shown in Fig. 3. The function $c(\kappa)$ was therefore chosen to be the same as the uniaxial compression curve of the concrete, only with a factor between the plastic strain and the hardening parameter $\kappa$ as shown in Fig. $7(b)$.

\section{Comparison with pull-out tests}

Pull-out tests of various kinds have been analysed with finite element models. The tests have been selected to show various types of failure: pull-out failure, splitting failure, pull-out failure after yielding of the reinforcement, rupture of the reinforcement bar, and cyclic loading. In all tests, the reinforcement is of type $\mathrm{K} 500 \phi 16$, and the concrete is of normal strength (the compressive cylinder strength varies from 25 to $35 \mathrm{MPa}$ ).

In all analyses, the concrete was modelled with a constitutive model based on non-linear fracture mechanics. Three slightly different material models have been used: a combined Drucker-Prager and Rankine elasto-plastic model, a Drucker-Prager together with a fixed crack model, and a rotating crack model based on total strain. ${ }^{8}$ One main difference between these material models is their behaviour for cyclic loading in tension. While the Rankine model gives unloading 


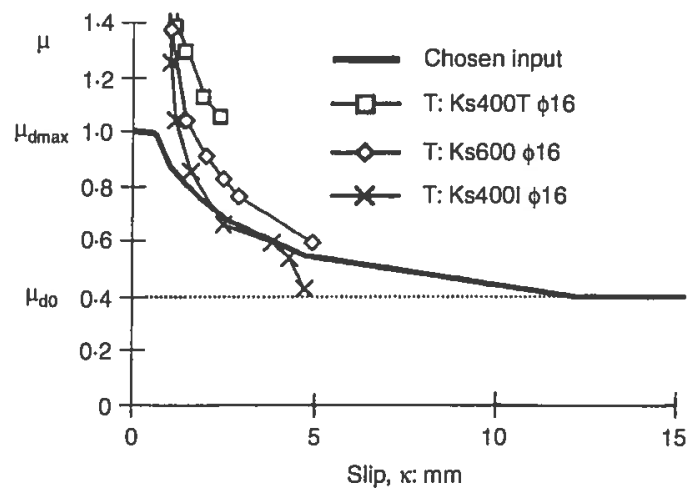

(a)

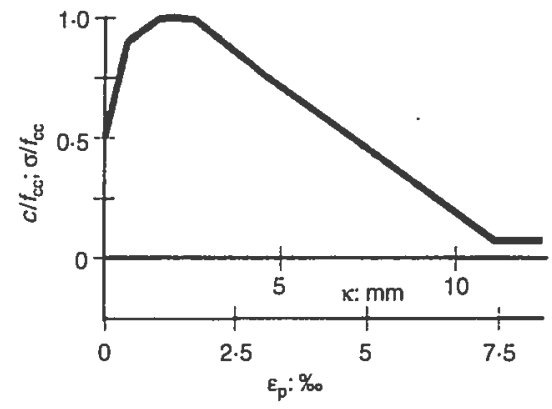

(b)

Fig. 7. (a) The coefficient of friction as a function of the slip evaluated from tests (T: Tepfers and Olsson ${ }^{6}$ ), together with the chosen function $\mu(\kappa)$. (b) Compressive stress versus plastic strain, and the function $c(\kappa)$

according to the elastic modulus, and then compressive stresses when the strain is positive, the crack models instead unload back to zero again (Fig. 8). In the following sections, the results from analyses with the combined Rankine and Drucker-Prager model are presented if nothing else is mentioned. When the different material models gave different results, this is discussed in the text.

Most of the finite element models were axisymmetric; the only exceptions are the eccentric pull-out tests of Magnusson. 9 The main advantage when using axisymmetric models is that the calculation time required for the analyses is dramatically decreased. One disadvantage of axisymmetric models is that a certain number of discrete radial cracks must be assumed. Close to the reinforcement bar, there are probably, at least in the beginning, quite a lot of cracks. Further out from the reinforcement bar, the number of cracks depends on the structure. In the following, the results from analyses with four radial cracks are shown, and when the assumed number of cracks has any influence on the results, it is discussed in the text.

Yielding was modelled using associated flow and isotropic hardening. The hardening of the DruckerPrager yield surface was evaluated from the shape of the uniaxial stress-strain relationship in compression,

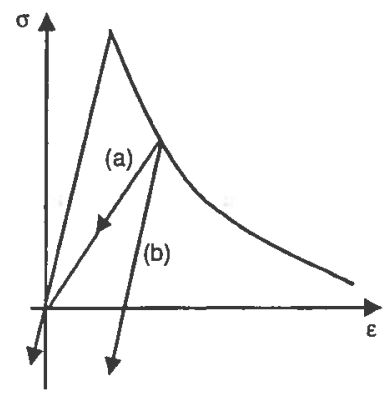

Fig. 8. Unloading/reloading in the material models used: (a) crack models; (b) Rankine model and was chosen to match typical test data presented by Kupfer and Gerstle. ${ }^{10}$ From the various measured compressive strengths, an equivalent compressive cylinder strength, $f_{\mathfrak{c c}}$, was evaluated. Other necessary material data for the concrete were calculated according to the expressions in $\mathrm{CEB}^{11}$ from $f_{\mathrm{cc}}$, and are shown in Table 1. The constitutive behaviour of the reinforcement steel was modelled by the Von Mises yield criterion with associated flow and isotropic hardening. The elastic modulus of the reinforcement was assumed to be $200 \mathrm{GPa}$ when it had not been measured.

\section{Pull-out failure}

In the tests carried out by the authors, ${ }^{7}$ reinforcement bars were pulled out of concrete cylinders surrounded by steel tubes. The steel tubes had a diameter of $70 \mathrm{~mm}$, a height of $100 \mathrm{~mm}$, and a thickness of $1.0 \mathrm{~mm}$. The embedment length of the reinforcement bars was $50 \mathrm{~mm}$. The tangential strains in the steel tubes were measured at three heights, together with the applied load and slip. Five tests were carried out, three in one direction and two in the other. When these tests were analysed, friction between the edges of the concrete and the support plates was introduced, assuming the coefficient of friction to be 0.4 . The friction at the supports did not influence the achieved load versus slip; however, the tangential strains in the analyses were slightly influenced (increasing the friction at the supports led to larger strain in the middle of the zone with bond, and lower strains close to the supports).

Results from the analyses with four assumed radial cracks, together with the finite element mesh used, are shown in Fig. 9. As can be seen, the choice of material model strongly affects the tangential strains after the maximum load. This is reasonable, since when the load decreases, the cracked concrete is unloaded. Since the Rankine model uses the modulus of elasticity for unloading, quite large residual strains are obtained, while the crack models that unload back to zero again give only small residual strains. As can be seen in Fig. 9, 
Table 1. Material data of the concrete in the analysed pull-out tests

\begin{tabular}{|c|c|c|c|c|c|c|}
\hline \multirow[t]{2}{*}{ Reference } & \multicolumn{2}{|c|}{ Compressive tests } & \multicolumn{4}{|c|}{ Material data used in the analyses } \\
\hline & Test specimen & $f_{\mathrm{cc}}: \mathrm{MPa}$ & $f_{\mathrm{cc}}: \mathrm{MPa}$ & $f_{\mathrm{ct}}: \mathrm{MPa}$ & $E_{\mathrm{c}}: \mathrm{GPa}$ & $G_{\mathrm{F}}: \mathrm{N} / \mathrm{m}$ \\
\hline Lundgren $^{7}$ & $150 \mathrm{~mm}$ cylinder, wet & $35 \cdot 6$ & $35 \cdot 6$ & $2 \cdot 7$ & $32 \cdot 9$ & 61 \\
\hline $\begin{array}{l}\text { Magnusson }^{9} \\
\text { Embedment length } 40 \mathrm{~mm} \\
\text { Embedment length } 220 \mathrm{~mm} \\
\text { Embedment length } 360 \mathrm{~mm} \\
\text { Eccentrically reinforced }\end{array}$ & $150 \mathrm{~mm}$ cylinder, wet & $\begin{array}{l}27.5 \\
30.6 \\
27.6 \\
29.4\end{array}$ & $\begin{array}{l}27 \cdot 5 \\
30 \cdot 6 \\
27 \cdot 6 \\
29 \cdot 4\end{array}$ & $\begin{array}{l}2 \cdot 2 \\
2 \cdot 4 \\
2 \cdot 2 \\
2 \cdot 3\end{array}$ & $\begin{array}{l}30 \cdot 0 \\
31 \cdot 3 \\
30 \cdot 2 \\
30 \cdot 9\end{array}$ & $\begin{array}{l}90 \\
96 \\
90 \\
94\end{array}$ \\
\hline Balázs and Koch ${ }^{12}$ & $150 \mathrm{~mm}$ cube, wet & $28-32$ & $25 \cdot 5$ & $2 \cdot 0$ & $29 \cdot 4$ & 58 \\
\hline
\end{tabular}

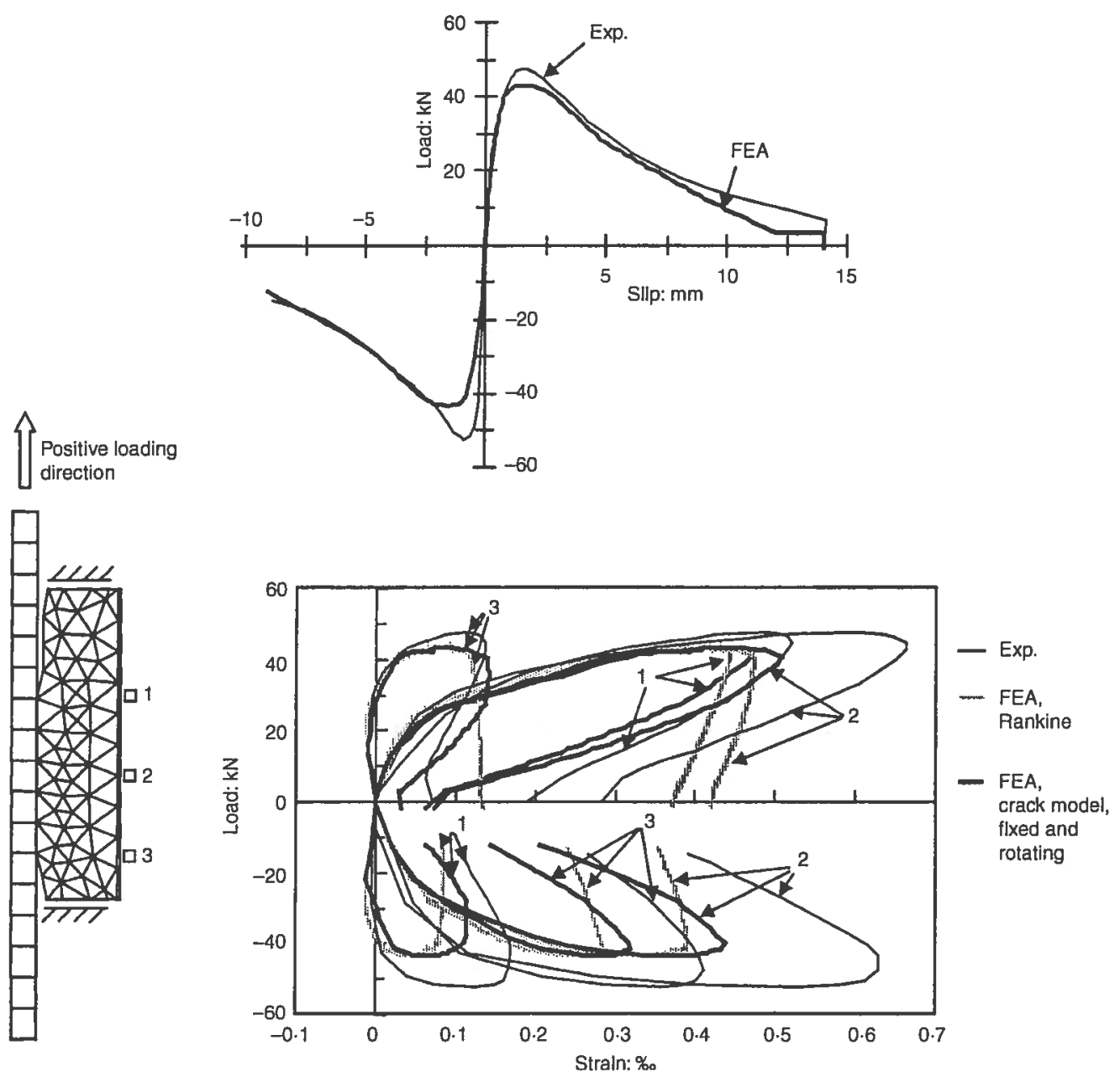

Fig. 9. Comparison between test results and results from the analysis of the monotonic loaded steel-encased pull-out tests. In the load versus slip, the different material models gave the same results, while the tangential strains differed

the experimental results lie- in between these two extreme cases. When the assumed number of radial cracks was two instead of four, the load versus slip was not affected. As can be expected, the tangential strain was, however, slightly higher when only two cracks were assumed. Instead of a maximum of about $0.50 \%$, the highest strain was about $0.55 \%$.

Pull-out tests carried out by Magnusson ${ }^{9}$ and Balázs Magazine of Concrete Research, 2000, 52, No. 1 and $\mathrm{Koch}^{12}$ have been analysed. Magnusson had concrete cylinders with a diameter of $300 \mathrm{~mm}$ and an embedment length of $40 \mathrm{~mm}$; Balázs and Koch had concrete specimens with a quadratic cross-section of $160 \times 160 \mathrm{~mm}$ and an embedment length of $80 \mathrm{~mm}$. In both cases, the concrete specimens were large enough to prevent splitting failure; thus, pull-out failures were obtained. Results from the analyses are compared with 
experiments in Fig. 10. As can be seen, a reasonably good agreement was obtained.

\section{Splitting failure}

Magnusson ${ }^{9}$ has also carried out pull-out tests on eccentrically reinforced specimens with varying stirrup configurations. The different stirrup configurations (without stirrups, with two and with four stirrups along the embedment length) led to splitting failures at various levels. In the test specimen with four stirrups, the stirrups gave enough confinement to obtain a ductile failure after splitting. In the analyses of these experiments, the stirrups were modelled as embedded reinfor-

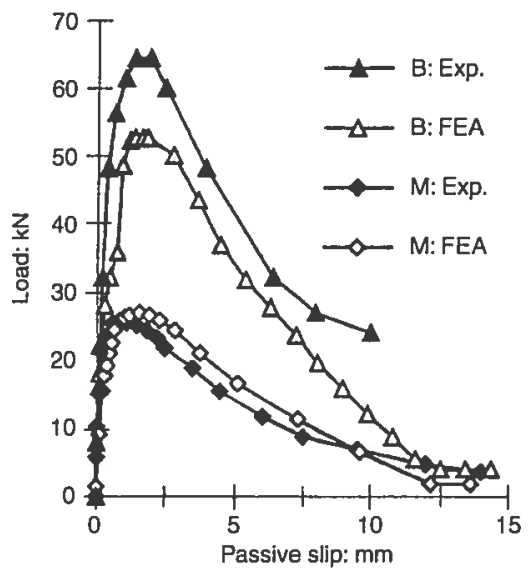

Fig. 10. Load versus slip in pull-out tests with short embedment length. B: Balázs and Koch; ${ }^{12}$ M: Magnusson ${ }^{9}$

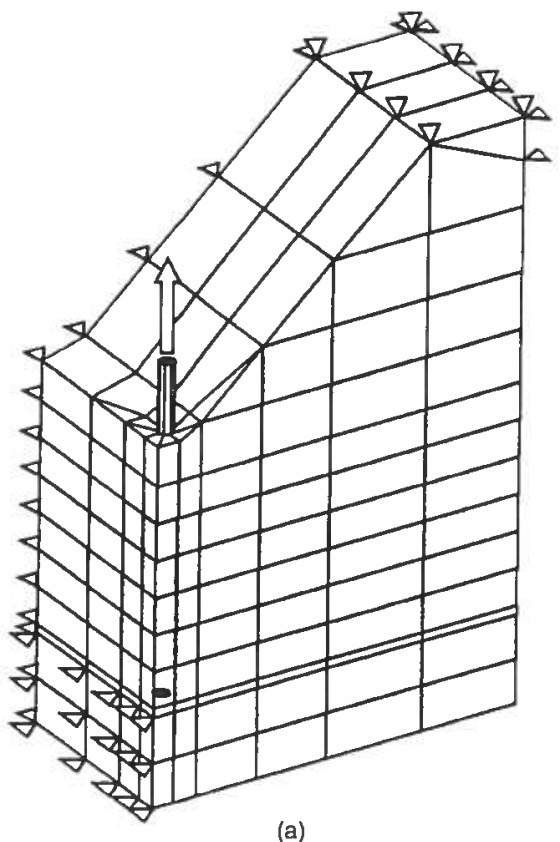

cement, meaning that complete interaction between the stirrups and the concrete was assumed. The finite element model, together with the boundary conditions, is shown in Fig. 11(a). Since a smeared crack model was used, the input of a characteristic length was needed. This length should be related to the size of one element. This is based on an assumption that a crack will localize in one element. In these analyses, however, the crack localized in two elements. The characteristic length was therefore estimated to be $40 \mathrm{~mm}$, based on the size of the area where the cracks localized (Fig. $11(b))$.

When these tests were analysed with Drucker-Prager combined with the fixed crack model, it was noted that the bond action caused splitting cracks that reached the outer surface of the concrete at about the maximum load that was measured in the tests. In the analyses, however, it was possible to further increase the load, which does not seem reasonable, especially not in the case without stirrups. This load increase was possible because the direction of the cracks was locked in the material model. Consequently, large stresses, about five times the tensile strength, could be transferred. With the use of rotating cracks, these large tensile stresses were prevented, and the correlation between the analyses and the experiments was improved, as can be seen in Fig. 12. It can be seen that even with the same embedment length, and when exactly the same input parameters were given for the interface, different loadslip curves were obtained depending on the modelled structure, in this case the number of stirrups. Compared with the measured response, the agreement is good,

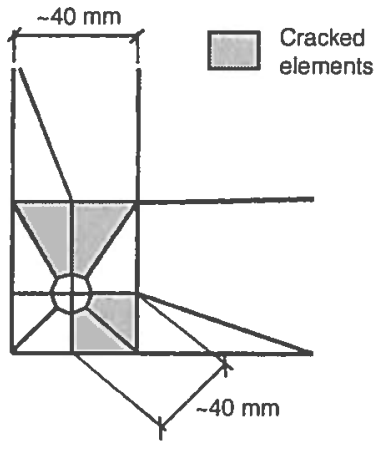

(b)

Fig. 11. (a) The finite element model of the pull-out tests on eccentrically reinforced specimens of Magnusson. ${ }^{9}$ (b) Localization of the main radial cracks in a cross-section 


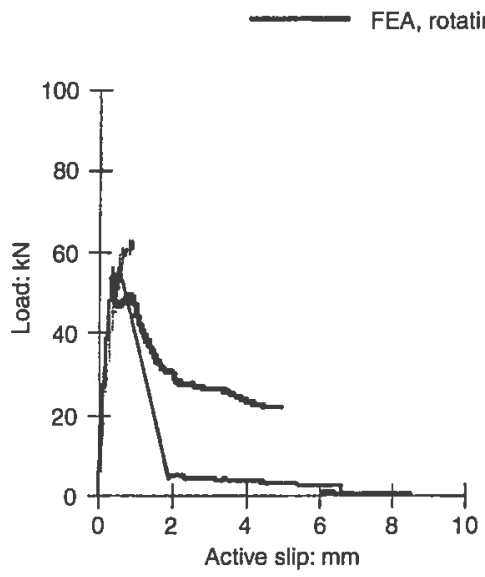

(a)

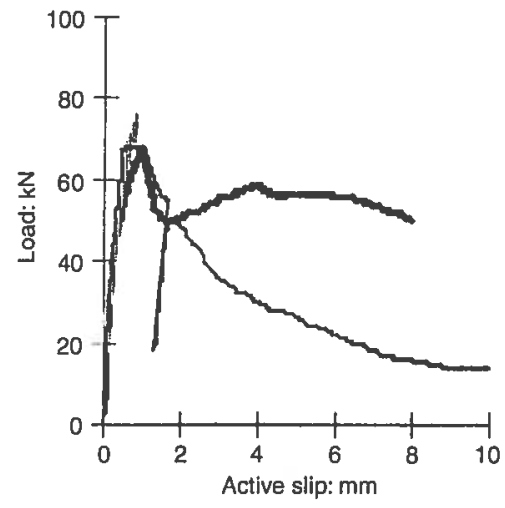

(b)

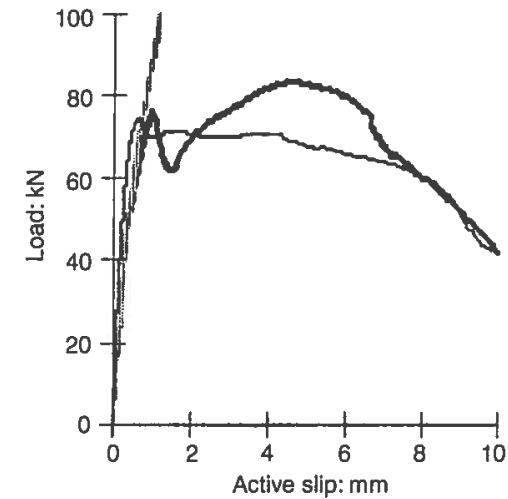

(c)

Fig. 12. Load versus slip in eccentrically reinforced pull-out tests: (a) without stirrups; (b) with two stirrups; (c) with four stimups

especially when considering the large scatter that is always obtained in pull-out tests.

\section{Yielding of the reinforcement}

Magnusson ${ }^{9}$ has also carried out pull-out tests where the reinforcement had an embedment length long enough to give yielding of the reinforcement. Two of these tests have been analysed, where the reinforcement was centrically placed in a concrete specimen of dimensions $400 \times 400 \mathrm{~mm}$. In one of the experiments, with an embedment length of $220 \mathrm{~mm}$, a pull-out failure after yielding of the reinforcement was obtained, and in the other one, with an embedment length of $360 \mathrm{~mm}$, rupture of the reinforcement bar occurred. As can be seen in Fig. 13, the same results were obtained in the analyses. In Fig. 14, the bond slip resulting from the analyses at various levels along the bar is shown. It can be seen that the bond stress decreased drastically when the reinforcement reached the yield plateau. This

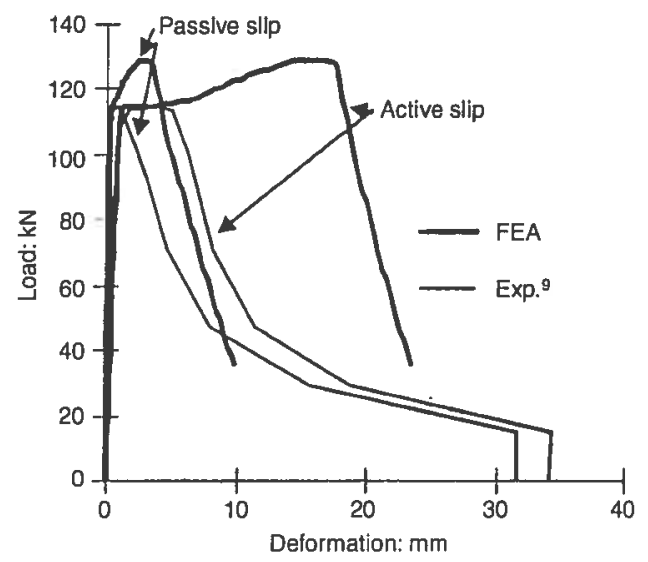

(a) is because the normal stress decreased when the radius of the reinforcement bar decreased. When the reinforcement began to harden again, a small bond capacity was obtained. This was possible since the decrease of the radius of the reinforcement was lower when the reinforcement hardened, and thus, normal stresses could be built up again.

\section{Cyclic pull-out tests}

The steel-encased pull-out tests carried out by the authors, ${ }^{7}$ briefly described in the pull-out failure section above, have also been carried out with reversed cyclic loading. The results from analyses of these experiments, using the fixed crack model for the concrete, are shown in Fig. 15. When the elasto-plastic Rankine material model is used for the concrete instead, only the tangential strains are affected, especially after a few load cycles. Instead of a residual value of about $0.05 \%$, about $0.4 \%$ is obtained. This can be

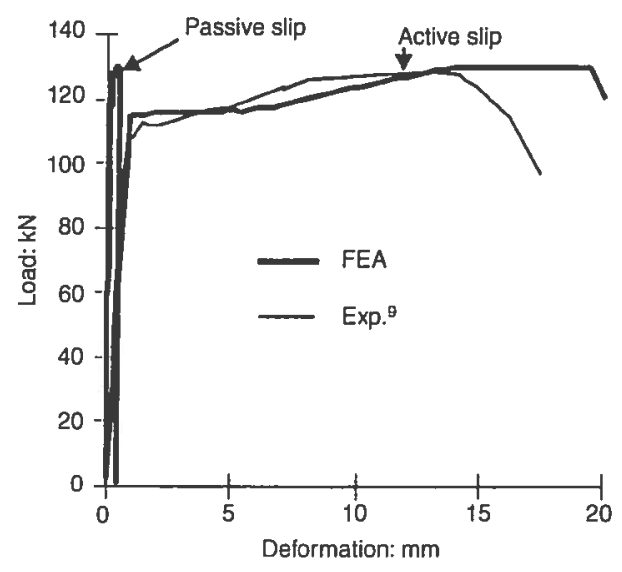

(b)

Fig. 13. Load versus slip in pull-out tests with long embedment. Experimental vesults from Magmusson: ${ }^{9}$ (a) embedment length $220 \mathrm{~mm}$; (b) embedment length $360 \mathrm{~mm}$ 


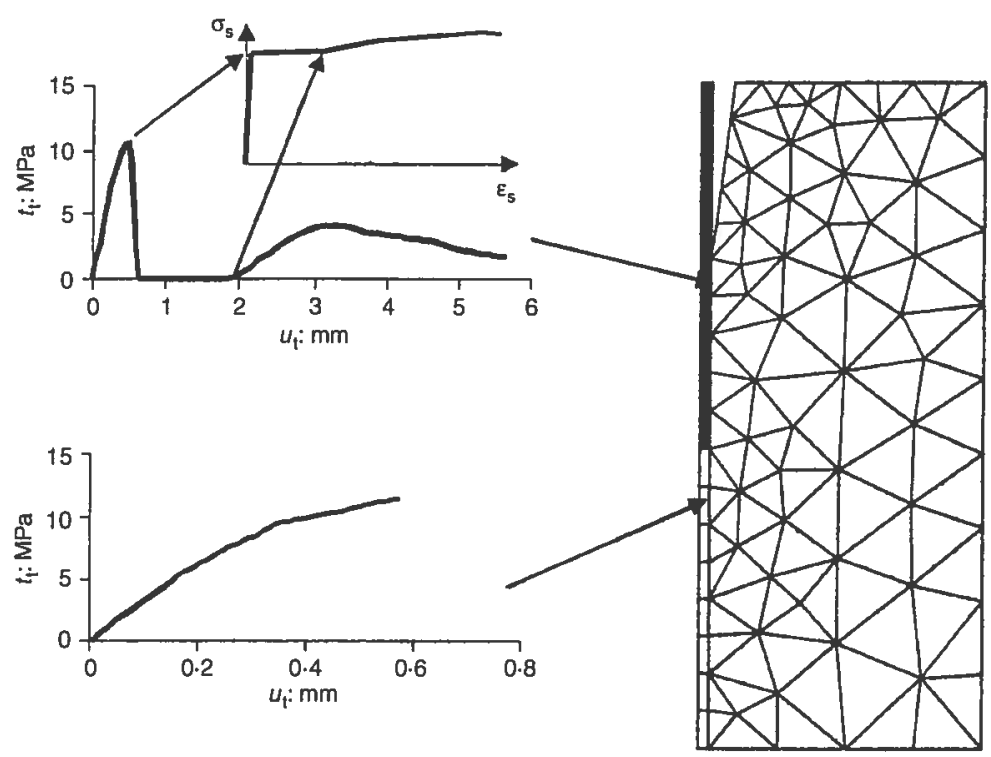

Fig. 14. Bond stress versus slip at various integration points along the bar in pull-out tests with embedment length $360 \mathrm{~mm}$. The reinforcment elements marked in grey reached yielding

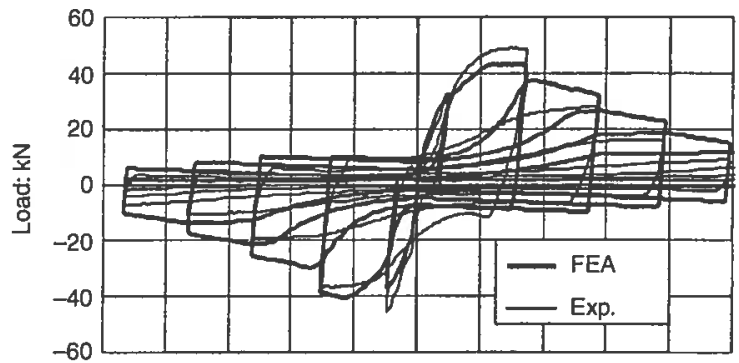

(a)

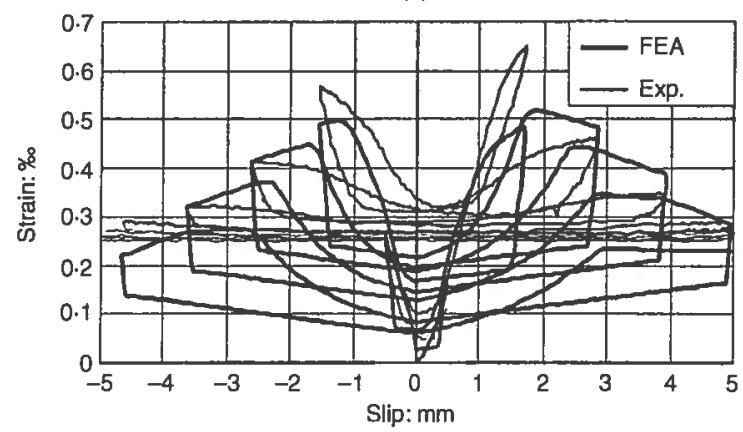

(b)

Fig. 15. Comparison between test results and results from the analysis of one cyclically loaded steel-encased pull-out test: (a) load versus slip; (b) tangential strain in the steel tube in the middle of the zone with bond

compared to what is measured in the tests: about $0.25 \%$. This shows that in order to improve the calibration of the bond model for cyclic loading, a concrete material model better suited for cyclic loading should be used.

62

\section{Conclusions}

A new model describing bond between deformed reinforcement bars and concrete has been developed. Since the model takes the three-dimensional splitting effect into account, the same input parameters will result in different load-slip curves, depending on whether the reinforcement starts yielding, and on the geometry and strength of the surrounding structure. Steel-encased pull-out tests, where the tangential strain in the steel tubes had been measured, were used to calibrate the model. The analyses show that the behaviour of the concrete material model for cyclic loading, or even for the first unloading, has a quite large influence on the tangential strains. In order to improve the calibration of the bond model for cyclic loading, a concrete material model better suited for cyclic loading should be used. There is, however, no such model that is possible to use in these analyses implemented in the finite element program today.

Depending on which material model was used for the concrete, slightly different results were obtained. The use of a fixed crack model, in analyses where splitting cracks determined the failure, resulted in larger loads than were measured in experiments. Since the direction of the cracks was locked in the material model, large stresses, about five times the tensile strength, could be transferred. With the use of rotating cracks, these large tensile stresses were prevented, and the correlation between the analyses and the experiments was improved.

Compared with the measured response from different experiments, the agreement is quite good. The failure mode is the same as in experiments in all of the 
analyses carried out. The bond model can also describe the behaviour for cyclic loading in a realistic way, and reasonably good agreement with experiments was found.

\section{References}

1. Tepfers R. A Theory of Bond Appied to Overlapped Tensile Reinforcement Splices for Deformed Bars. Division of Concrete Structures, Chalmers University of Technology, Göteborg, 1973, Publication 73:2.

2. ENGSTRöM B. Ductility of Tie Connections in Precast Structures. Chalmers University of Technology, Division of Concrete Structures, Göteborg, 1992, Publication 92:1.

3. Cox J. V. Development of a Plasticity Bond Model for Reinforced Concrete-Theory and Validation for Monotonic Applications. Naval Facilities Engineering Service Center, Port Hueneme, USA, 1994.

4. ÁKesson M. Fracture Mechanics Analysis of the Transmission Zone in Prestressed Hollow Core Slabs. Division of Concrete Structures, Chalmers University of Technology, Göteborg, 1993, Publication 93:5.

5. LundgRen K. Modelling of Bond: Theoretical Model and Ana- lyses. Chalmers University of Technology, Division of Concrete Structures, Göteborg, 1999, Report 99:5.

6. TEPFERS R. and OLsSON P. $\AA$. Ring test for evaluation of bond properties of reinforcing bars. Bond in Concrete Proceedings (CEB), Riga, 1992, pp. 1-89-1-99.

7. Lundgren K. Steel-encased Pull-out Tests Subjected to Reversed Cyclic Loading. Chalmers University of Technology, Division of Concrete Structures, Göteborg, 1998, Report 98:9.

8. TNO Building and Construction Research. DIANA Finite Element Analysis, Users' Manual release 7, Hague 1998.

9. MAGNusson J. Bond and Anchorage of Deformed Bars in HighStrength Concrete. Division of Concrete Structures, Chalmers University of Technology, Göteborg, 1997, Publication 97:1.

10. Kupfer H. B. and Gerstle K. H. Behaviour of concrete under biaxial stresses. Joumal of the Engineering Mechanics Division, ASCE, 1973, 99, 853-866.

11. CEB. CEB-FIP Model Code 1990. CEB Bulletin d'lnformation No. 213/214, Lausanne 1993.

12. BALÁzS G. and $\mathrm{KoCH} R$. Bond characteristics under reversed cyclic loading, Otto Graf Journal, 1995, 6, 47-62.

Discussion contributions on this paper should reach the editor by 1 July 2000 